\title{
trabalhonecessário
}

issn: $1808-799 \mathrm{X}$

ano 8 - número 10 - 2010

\section{IMPLICAÇÕES DA CRISE CAPITALISTA NO CAMPO TEÓRICO: PÓS- MODERNIDADE E EXCLUSÃO SOCIAL DAS PESSOAS COM DEFICIÊNCIA ${ }^{1}$}

Leonardo Docena Pina - leodocena@yahoo.com.br André Silva Martins (co-autor) - andremartinsjf@gmail.com

Este texto realiza um debate teórico com autores que abordam, sob a ótica pós-moderna, as condições de inferioridade social que atingem as pessoas com deficiência. $O$ objetivo é mostrar que o reordenamento capitalista do final do século XX interferiu no campo teórico, contribuindo para fazer a 'exclusão social' dos deficientes assumir a forma de um fenômeno que não emana das relações sociais de produção da existência humana.

A crise capitalista expressa, na década de 1970, pela falência do regime de acumulação fordista, fez com que importantes setores da classe burguesa implementassem uma tentativa de recuperar os patamares de expansão anteriores. Como expressão dessa tentativa, pode-se destacar a passagem do 'regime de acumulação fordista ao regime de acumulação flexível' (Harvey, 2007). Essa modificação no regime de acumulação do capital demandou, também, sob o ponto de vista do bloco no poder, uma mudança no modo de regulamentação da vida. Daí a difusão do pós-modernismo como modo de vida a ser seguido pelo conjunto da sociedade.

De acordo com Chauí (2001), o pós-modernismo, que assume a forma de ideologia específica do neoliberalismo, repudia os princípios analíticos que nos permitem compreender os fenômenos sociais do capitalismo com base na totalidade concreta. Assim, diferentes acontecimentos sociais tendem a ser compreendidos de forma imediata, sem transcender sua manifestação aparente. 
issn: $1808-799 X$

ano 8 - número 10 - 2010

É importante salientar que, embora a aparência dos fenômenos integre sua composição, ela, por si só, não revela, de imediato, o produto concreto da realidade (Kosik, 1985). O pós-modernismo desconsidera esse fato, reduzindo-se à compreensão fenomênica do real. Evidência disso é o caso da segregação das pessoas com deficiência. Em essência, esse fenômeno é resultado de procedimentos de inclusão forçada estabelecidos para garantir a imposição de comportamentos, normas, condutas, valores e outros requisitos necessários ao contínuo acúmulo de capital. Porém, a referida segregação se apresenta imediatamente aos olhos dos seres humanos como fenômeno dissociado da totalidade concreta. A aparência é a de que se trata de uma 'exclusão', proveniente de processos dissociados da dominação de classe. Seguindo a tendência de prezar a superfície do aparecer social, intelectuais pautados no pós-modernismo formulam o 'paradigma da exclusão', a partir do qual o referido fenômeno é explicado sem os devidos vínculos com os processos históricos: a 'exclusão' passa a ser entendida como um dos efeitos de supostos micropoderes capilares desvinculados das relações sociais de produção. Esse entendimento mantém lacunas que debilitam a luta pela superação do capitalismo, já que, ao dificultar o entendimento radical das condições de exclusão, as determinações impostas pelas relações sociais capitalistas tendem a ser mascaradas.

Ao mostrar que o reordenamento capitalista do final do século XX interferiu no debate sobre a segregação das pessoas com deficiência, o presente texto busca inserir-se no debate sobre a 'exclusão social' de modo a contribuir para a articulação da classe trabalhadora em torno de um projeto que vise superar a sociedade capitalista. Assim, o texto explicita, no plano teórico, um problema ligado à formação humana e às práticas educativas no século XXI a partir das repercussões do pósmodernismo e da noção de exclusão social na atual configuração do capitalismo. A abordagem de tal problema é realizada com base no materialismo histórico e configura uma análise crítica sobre as mediações teoria, formação humana, trabalho, educação e deficiência com o objetivo de indicar novas possibilidades de análise das questões anteriormente mencionadas, que tomam forma na dinâmica capitalista no século XXI. 
issn: $1808-799 \mathrm{X}$

ano 8 - número 10 - 2010

\section{O aparecer imediato da 'exclusão'}

Santos (2007, p.63) afirma que Michel Foucault foi de grande importância, com seus estudos sobre a normalização, para ver como se cria a exclusão: "um sistema em que alguém fica totalmente de fora". Essas palavras de Boaventura de Sousa Santos são bastante ilustrativas para evidenciar dois aspectos. O primeiro refere-se ao fato de que os estudos realizados por Foucault têm sido considerados de grande importância para entender como se cria o fenômeno denominado de 'exclusão'. O segundo diz respeito a esse modo de se entender a 'exclusão', como um sistema em que alguém fica totalmente de fora. Esses dois aspectos serão abordados neste trabalho, a começar pela influência de Foucault no entendimento desse fenômeno social.

Fontes (2005) explica que, especialmente a partir da década de 1960, sobretudo a partir das obras de Michel Foucault, Gilles Deleuze e Félix Guattari, foi aberto um imenso painel sobre modalidades de banimento, encarceramento e segregação que, exercidas de forma regular e 'naturalizadas', constituíram uma longa e penosa prática social estabelecida a partir do século XVII. Concomitantemente com o estudo histórico dos processos constitutivos da formação da sociedade moderna, buscava-se evidenciar modalidades de segregação até então tidas como 'normais' ou 'naturais' (Fontes, 2005).

Uma das modalidades de segregação cuja análise teve grande impacto refere-se aos problemas diretamente relacionados ao internamento psiquiátrico. Segundo Fontes (2005), esse tema não só denunciava práticas de isolamento e reclusão da doença mental como apontava para o deslizamento sistemático entre contestação social e 'anormalidade', em uma prática que, generalizada na União Soviética, disseminava-se na maioria dos países. A análise do sistema penal e hospitalar mostrava que "a punição por confinamento ou encarceramento constituiria, a rigor, a norma social e não uma exceção, paradoxalmente reforçada a partir da generalização do liberalismo" (Fontes, 2005, p.35, grifos da autora). A análise ainda mostrava que a segregação configurada pela reclusão psiquiátrica englobava não só aqueles atingidos por graus diversos de sociabilidade como 
issn: $1808-799 \mathrm{X}$

ano 8 - número 10 - 2010

aqueles que contestavam as formas políticas dominantes. Em virtude da fertilidade da proposição, surgiram trabalhos dedicados a analisar, por exemplo, a segregação das mulheres do universo político ao longo do tempo e a estigmatização de grupos sociais em razão de profissões, de doenças, de local ou moradia ou do vínculo religioso, étnico ou linguístico. Assim, ainda de acordo com Fontes (2005), demonstravam-se como expressivas parcelas da população eram mantidas em situações de inferioridade social por meio de um discurso de poder tendente a hierarquizar e reproduzir formas de controle social. Essas situações de inferioridade social foram designadas pelo termo exclusão.

Em Michel Foucault, o termo exclusão encontrava-se diretamente associado a controle social e disciplinarização, à circulação de poderes e constituição de hierarquias, não necessariamente sincronizados nem dependentes das formas pelas quais se justificava ou circulava o poder econômico. Assim explica Fontes (2005, p.35-36):

O termo exclusão - utilizado por Foucault ao lado de expressões como banimento, reclusão e expulsão - constituía um viés pelo qual o autor demonstrava os efeitos de seu eixo principal de reflexão, as formas de distribuição de poder, com ênfase na instauração de uma sociedade disciplinar, com modalidades específicas de disseminação e radiação das formas de controle social. Assim, foi largamente empregado para designar aspectos específicos, pontuais, culturalmente diversos do exercício de poderes no interior de diferentes sociedades, caracterizando a circulação de poder e evidenciando a cristalização de pequenos poderes que, agindo na sociedade e perfeitamente disseminados, reproduziam e amplificavam formas "naturalizadas" de segregação social. Com isso, permitia identificar o estabelecimento de múltiplas hierarquias, não necessariamente sincronizadas ou dependentes das formas pelas quais se justificava ou circulava o poder econômico.

É importante evidenciar que, para Foucault, o fenômeno da exclusão é entendido como um dos efeitos das formas de distribuição de poder por ele descritas. Em virtude disso, o resgate do modo como esse autor compreende a 
issn: $1808-799 \mathrm{X}$

ano 8 - número 10 - 2010

temática do poder pode evidenciar a ótica pela qual ele analisa o fenômeno da exclusão.

Conforme explica Veiga Neto (2005, p.144-145), "Foucault pulveriza e descentra o poder", ou seja, "não o compreende como algo que emane de um centro - instituições ou Estado -, como algo que se possua e que tenha uma natureza ou substância própria, unitário e localizável”. Essa ideia foucaultiana de que o poder não emana de um centro capta um determinado aspecto da realidade: trata-se do fato de que o poder é resultado das relações sociais e, dessa forma, emana do modo de vida, mais especificamente, da forma como os seres humanos se organizam na sociedade para produzir sua existência material e imaterial. Entendendo que o poder é uma relação, pode-se afirmar que ele não é uma coisa a ser conquistada mediante um simples golpe, visto que o poder se exerce, não se dá, nem se troca. Daí Foucault entender que

o poder não existe (no sentido definido do artigo e no sentido duro do verbo), mas existem práticas em que ele se manifesta, atua, funciona e se espalha universal e capilarmente. (...) o poder não se dá, não se troca nem se retoma, mas se exerce, só existe em ação (Veiga-Neto, 2005, p.148, grifos do autor).

No entendimento de Foucault, "o poder não é principalmente manutenção e reprodução das relações econômicas, mas acima de tudo uma relação de força" (Veiga-Neto, 2005, p.148). Sobre a relação de força a que se refere o autor, é importante salientar que

as forças de que fala Foucault - e de que falava também Nietzsche não estão nas mãos de alguns atores ou de algum grupo que as exerçam sobre outros. Elas não são colocadas em movimento como resultado de arranjos políticos ocultos; elas não emanam de algum centro, como o Estado (nem mesmo o absolutista). Ao contrário, tais forças estão distribuídas difusamente por todo o tecido social (VeigaNeto, 2005, p.73). 
Aparentemente, pode-se considerar que Foucault trouxe importantes contribuições à temática do poder, sobretudo pela sua contribuição para difundir o entendimento de que o poder é uma relação social. Porém, dois aspectos devem ser ressaltados.

A descoberta da concepção relacional de poder é habitualmente atribuída pela Academia a Michel Foucault. Dessa forma, é silenciado que, quarenta anos antes de Foucault expor sua concepção em Microfísica do poder, Antônio Gramsci (2000), seguindo Lenin, já tinha defendido o poder e a política 'em termos de relações', não em geral, mas como relações de força, fato irrefutável da teoria política que, contudo, não desmerece a correta ênfase foucaultiana naquela dimensão relacional (Kohan, 2007).

Outro aspecto a ser destacado diz respeito ao fato de que, por um lado, a teoria da microfísica do poder (Foucault, 1999) permitiu, ao pensamento político, avançar no sentido de desmistificar as visões que, concebendo o poder como uma coisa materializada no aparelho estatal, subestimam as múltiplas dimensões das relações de poder (Sader, 2003). Por outro lado, a teoria de Foucault 'deshistoriciza' completamente o poder, hipostasiando e abstraindo todo o seu vínculo com as relações de produção (Kohan, 2007).

Nas sociedades capitalistas, as relações de poder emanam das relações sociais de produção. Tais relações ganham forma na organização e dinâmica da sociedade civil até atingir o aparelho estatal, sendo o seu resultado o fundamento para a dominação de classe. Embora o aparelho estatal não seja a única e mais importante instância de exercício do poder, esvaziar ou negar sua função educativa, coercitiva e/ou de convencimento em nada contribui para explicar a problemática da dominação na sociedade capitalista.

Foucault não busca evidenciar que a classe dominante, para manter sua hegemonia, precisa criar uma unidade, difundindo, por todo o tecido social, as ideias 
issn: $1808-799 \mathrm{X}$

ano 8 - número 10 - 2010

e comportamentos capazes de organizar e direcionar o conjunto da sociedade ${ }^{2}$. Ao invés de compreender as relações de poder distribuídas difusamente pelo tecido social a partir da hegemonia da classe dominante, o autor nos conclama a realizar uma análise ascendente do poder. Essa forma de análise consiste em

partir dos mecanismos infinitesimais que têm uma história, um caminho, técnicas e táticas e depois examinar como estes mecanismos de poder foram e ainda são investidos, colonizados, utilizados, subjugados, transformados, deslocados, desdobrados, etc., por mecanismos cada vez mais gerais e por formas de dominação global. Não é a dominação global que se pluraliza e repercute até embaixo (Foucault, 1999, p.184).

Sob a ótica do autor, não é a dominação global, posta em prática pela burguesia, que repercute 'até embaixo', nos poros da sociedade. Foucault (1999) supõe que as múltiplas formas de dominação que ocorrem na sociedade não emanam dos interesses da classe, mas de mecanismos próprios. Além de defender a análise ascendente do poder, que não vincula as formas de dominação à totalidade da vida social, o autor ainda critica o que denomina de 'análise descendente' do poder. Em suas palavras:

Creio que deva ser analisada a maneira como os fenômenos, as técnicas e os procedimentos de poder atuam nos níveis mais baixos; como estes procedimentos se deslocam, se expandem, se modificam; mas sobretudo como são investidos e anexados por fenômenos mais globais; como poderes mais gerais ou lucros econômicos podem inserir-se no jogo destas tecnologias de poder que são, ao mesmo tempo, relativamente autônomas e infinitesimais. Para que isto fique mais claro pode-se dar o exemplo da loucura. A análise descendente, de que se deve desconfiar, poderia dizer que a burguesia se tornou a classe dominante a partir do final do século XVI e início do século XVII; como é então possível deduzir desse fato a internação dos loucos? A dedução é sempre possível, é sempre fácil e é exatamente esta a crítica que Ihe faço. Efetivamente, é fácil mostrar como se torna obrigatório desfazer-se do louco justamente porque ele é inútil na produção industrial. Poder-se-ia dizer a mesma coisa a respeito da sexualidade infantil e, de resto, foi o que algumas 
issn: $1808-799 \mathrm{X}$

ano 8 - número 10 - 2010

pessoas fizeram, como por exemplo, e até certo ponto, W. Reich: a partir da dominação da classe burguesa, como é possível compreender a repressão da sexualidade infantil? Muito simplesmente: já que o corpo humano se tornou essencialmente força produtiva a partir dos séculos XVII e XVIII, todas as formas de desgaste irredutíveis à constituição das forças produtivas manifestando, portanto, sua própria inutilidade - foram banidas, excluídas e reprimidas (Foucault, 1999, p.184).

Foucault (1999), acreditando ser possível 'deduzir' qualquer coisa do fenômeno geral da dominação burguesa, opta por realizar suas análises sem buscar, nos interesses das classes, a origem das formas de dominação exercidas na sociedade:

\begin{abstract}
Creio que é possível deduzir qualquer coisa do fenômeno geral da dominação da classe burguesa. O que faço é o inverso: examinar historicamente, partindo de baixo, a maneira como os mecanismos de controle puderam funcionar; por exemplo, quanto à exclusão da loucura ou à repressão e proibição da sexualidade, ver como, ao nível efetivo da família, da vizinhança, das células ou níveis mais elementares da sociedade, esses fenômenos de repressão ou exclusão se dotaram de instrumentos próprios, de uma lógica própria, responderam a determinadas necessidades; mostrar quais foram seus agentes, sem procurá-los na burguesia em geral e sim nos agentes reais (que podem ser a família, a vizinhança, os pais, os médicos, etc.) e como estes mecanismos de poder, em dado momento, em uma conjuntura precisa e por meio de um determinado número de transformações começaram a se tornar economicamente vantajosos e politicamente úteis (Foucault, 1999, p.185).
\end{abstract}

Foucault (1999, p.185) entende, por exemplo, que "não foi a burguesia que achou que a loucura deveria ser excluída ou a sexualidade infantil reprimida". No seu entendimento, os mecanismos de 'exclusão da loucura' e de vigilância da sexualidade infantil evidenciaram um lucro econômico e uma utilidade política, que, de repente, tornaram-se naturalmente colonizados e sustentados por mecanismos globais do sistema do Estado. Na verdade, o que Foucault (1999) defende é a análise dos fenômenos da sociedade sob outra ótica que não a da totalidade 
issn: $1808-799 \mathrm{X}$

ano 8 - número 10 - 2010

concreta. Assim, torna-se possível atingir a compreensão de que o poder em localidades, contextos e situações sociais distintos é construído de forma independente da cultura gerada nos processos de produção da existência humana. Isso permite ao autor compreender diferentes organismos da sociedade como lugares em que uma organização dispersa e não integrada é construída independentemente de qualquer estratégia sistemática e de domínio de classe.

Já foi possível compreender que Foucault, embora 'descoisifique' o poder, não consegue ver que, em uma sociedade de classe, os interesses distintos, organizados na sociedade civil, são inseridos na aparelhagem estatal. O intelectual também não consegue entender que os micropoderes que penetram no tecido social, difundidos em modo de vida, criam uma cultura baseada nos interesses de determinada classe. Nesse ponto, torna-se possível afirmar que a teoria da microfísica do poder pouco contribui para elucidar os complexos e sutis processos de dominação de classe na sociedade capitalista. Além do mais, trata-se de uma teoria ancorada no pós-modernismo ${ }^{3}$.

De acordo com Chauí (2001), o pós-modernismo instaurou, no campo teórico, a chamada crise da razão, que se explicita, principalmente, a partir de cinco aspectos. Dentre os aspectos mencionados por Chauí (2001) que caracterizam o pós-modernismo, encontra-se a

negação de que o poder se realiza a distância do social por meio de instituições que lhe são próprias, fundadas tanto na lógica da luta de classes e da dominação, quanto nas ações emancipatórias. Em seu lugar surgem as idéias de micropoderes capilares, que disciplinam a sociedade e políticas que se realizam sem as mediações institucionais, resultando, no primeiro caso, em ações fragmentadas que terminam em meras demandas, e, no segundo, em reforço dos populismos e dos fascismos (Chauí, 2001, p.154).

É a partir da concepção pós-moderna de poder que Foucault identificava o estabelecimento de múltiplas hierarquias, que, a seu ver, não estariam 
issn: 1808-799X

ano 8 - número 10 - 2010

necessariamente sincronizadas ou dependentes das formas pelas quais se justificava ou circulava o poder econômico. Dessa forma, o intelectual visava "ressaltar os efeitos segregadores de práticas não econômicas", "desnudar a reprodução e a criação de diferenças estigmatizantes e hierarquizantes, para além de clivagens clássicas calcadas no aspecto econômico ou centradas na relação capital-trabalho" (Fontes, 2005, p.36, grifos da autora).

Seguindo a tendência de tratar modalidades de segregação para além de clivagens clássicas calcadas na dominação de classe, Marques (2001), L. Marques (2001), além de Marques e Marques (2003) apresentam reflexões sobre a chamada "exclusão" dos indivíduos com deficiência, processo evidenciado pela segregação dessas pessoas em instituições especializadas ${ }^{4}$.

Marques (2001) parte do princípio de que o entendimento dos novos rumos que vem tomando a humanidade, inclusive no que se refere à temática da deficiência, depende do modo como vem sendo compreendida a própria vida. Sua compreensão é a de que o "descortinamento do processo de transição entre o pensamento da Modernidade e os preceitos Pós-Modernos" constitui uma condição básica para a tentativa de se responder às questões por ele formuladas (Marques, 2001, p.29). Daí a adoção do deslocamento do pensamento moderno ao 'Atual' como pano de fundo de sua análise ${ }^{5}$

Sob a ótica dos referidos autores, a 'padronização do normal' e a segregação dos desviantes é marca do 'pensamento Moderno', no qual as formas de se conceber o mundo e as relações entre os seres humanos estariam calcadas no princípio do universal, nas dicotomias normal/anormal, certo/errado, bom/ruim (L. Marques, 2001). Vale ressaltar, segundo Fontes (2001), que 'universal' refere-se a tudo que pode ser partilhado pelas pessoas (em princípio, pois, demonstrável), independentemente de sua origem, crença, filiação etc. A autora explica que a enunciação da gravidade, por exemplo, é universal, tanto em sua aplicabilidade quanto pela possibilidade dada a qualquer indivíduo, detentor de conhecimentos (uma forma de linguagem), aceder à sua formulação e, eventualmente, contestá-la a partir de seus próprios pressupostos. Para Marques e Marques (2003), o 
issn: $1808-799 \mathrm{X}$

ano 8 - número 10 - 2010

'pensamento Atual', não mais fundado no universal, mas na diversidade, conduziria às práticas de reconhecimento e respeito pelo outro, que superariam aquelas predominantes na 'Modernidade'6.

A partir dessa ótica, Marques (2001) afirma que os indivíduos portadores de deficiência e condutas típicas compõem uma categoria colocada à margem do processo social. Dentre os aspectos abordados pelo autor que evidenciam a problemática de grupos historicamente discriminados, encontra-se a temática da normalidade/anormalidade.

Exatamente nesse ponto reside um grande mérito do estudo de Marques (2001). Suas reflexões evidenciam que a segregação das pessoas com deficiência e condutas típicas, assim como a segregação de outros grupos desviantes, constituiu um processo perverso que se assenta na criação da figura do anormal. $O$ autor explica que, a partir da criação do padrão de normalidade, os desviantes desse padrão passaram a ser considerados anormais. Em virtude disso, os indivíduos com deficiência, assim como outros casos de desvio do padrão de normalidade, foram sendo segregados em instituições especializadas. No interior dessas instituições, vários grupos sociais mantinham-se à margem do convívio com as pessoas consideradas normais, configurando o que se convencionou denominar de paradigma da exclusão (Marques, 2001). Para consolidar a segregação, tais instituições apresentaram como finalidade manifesta a redução das mazelas vividas por aqueles que se desviavam do padrão de normalidade. Dessa forma, a segregação aparecia como algo benéfico aos desviantes, sobretudo pela atuação dos 'especialistas' (Marques, 2001) que formularam e difundiram o discurso de que as instituições especializadas serviam para proteger, educar, reabilitar ou integrar, na sociedade, cada grupo desviante.

O olhar clínico dos especialistas atingiu, inclusive, o sistema educacional, resultando na aplicação de estereótipos e na segregação dos educandos desviantes nas chamadas escolas especiais, que funcionavam em conformidade com a chamada Educação Especial. Conforme explicam Glat e Fernandes (2005), o trabalho nas escolas especiais, sob o enfoque médico ou clínico, era organizado 
issn: $1808-799 \mathrm{X}$

ano 8 - número 10 - 2010

com base em um conjunto de terapias individuais (fisioterapia, fonoaudiologia, psicologia, psicopedagogia etc.) e com pouca ênfase dada à atividade acadêmica, já que, nessa instituição, a educação escolar não era compreendida como necessária, ou mesmo, possível, sobretudo para os educandos com deficiências cognitivas e/ou sensoriais severas. Dessa forma, o trabalho era desenvolvido como um processo de 'prontidão para a alfabetização', sem muitas expectativas quanto à capacidade de esses indivíduos se desenvolverem academicamente e ingressarem na cultura formal (Glat e Fernandes, 2005). Mesmo com o desenvolvimento teórico-prático ocorrido nas décadas de 1970 e 1980, do qual resultou uma mudança de enfoque da perspectiva do 'modelo médico' ao 'modelo educacional', a educação especial não deixou de funcionar como um serviço paralelo, com métodos ainda de forte ênfase clínica e currículos próprios (Glat e Fernandes, 2005).

Há de se concordar com Marques (2001) no que diz respeito ao fato de que essa forma de funcionamento das escolas especiais, vale dizer, a partir da criação de uma 'estrutura paralela' para atender às supostas necessidades dos deficientes, constitui um processo perverso, visto que a referida estrutura não teria sido criada para beneficiar as pessoas com deficiência, mas, antes, para separá-las dos outros educandos. Tal fato pode ser evidenciado pelas reflexões de Ferreira e Glat (2005). As autoras apontam que as escolas e classes especiais implantadas nas décadas de 1970 e 1980 atuaram mais como espaços de segregação para aqueles que não se enquadravam no sistema regular de ensino do que como possibilidade de promover o ingresso dos educandos com deficiência no ensino público, tal como era proclamado em seus objetivos.

Em síntese, pode-se dizer que, por trás da finalidade manifesta de atender às supostas necessidades dos indivíduos com deficiência, as instituições especializadas, dentre elas a escola especial, assumiam a função de distanciar o deficiente do convívio social, difundindo uma imagem negativa em relação a ele (Marques, 2001). Dito de outra forma, a segregação dos desviantes do padrão de normalidade, dentre os quais se encontram as pessoas com deficiência, não ocorria para atender às supostas necessidades dos indivíduos atendidos nas instituições 
issn: $1808-799 \mathrm{X}$

ano 8 - número 10 - 2010

especializadas, mas, sim, para manter distante do convívio com os indivíduos considerados normais aqueles que supostamente significavam um risco à saúde do corpo social.

Em virtude disso, torna-se evidente a necessidade de se inserir na luta pela superação de tais práticas. Entretanto, é sobre a 'Modernidade' e não sobre o bloco que detém a direção do processo histórico que autores pós-modernos costumam concentrar a 'origem' do mecanismo de criação da figura do anormal e das ações discriminatórias e segregadoras geradas por esse processo. Enquanto o 'mundo Atual', com o pensamento pós-moderno, pautado na diversidade, conduziria às práticas de reconhecimento e respeito pelo outro, a 'Modernidade', sob o ponto de vista desses autores, seria responsável pelo processo de segregação de grupos historicamente discriminados, a exemplo dos indivíduos com deficiência:

a Modernidade caracterizou-se pela delimitação do espaço passível de ocupação por cada indivíduo na sociedade [...]. Assim, a posição de cada um estaria definida conforme o espaço a ele destinado em um determinado ambiente sociocultural. A deficiência, entendida como desvio da normalidade constituiu, como se pôde perceber, um objeto permanente de práticas de vigilância e de isolamento sociais. Tais atitudes se manifestariam no cotidiano das pessoas nas formas do preconceito e da discriminação. $O$ isolamento das pessoas com deficiência em asilos, internatos e hospitais representa a materialização do que ora é discutido (L. Marques, 2001, p.51).

Afirmam ainda que:

O discurso da Modernidade sobre as pessoas com deficiência esteve sempre calcado no entendimento da deficiência como desvio da norma, ou, em outras palavras, como não ajustamento aos padrões ideologicamente estabelecidos como normais (Marques e Marques, 2003, p.229).

Apesar de a modernidade ser um período histórico delimitado por relações sociais específicas, geradas pelo modo capitalista de produção da existência 
issn: $1808-799 \mathrm{X}$

ano 8 - número 10 - 2010

humana, para alguns autores, a modernidade torna-se mera abstração, sendo desvinculada da história real produzida pelos seres humanos em seus espaços concretos de realização da vida. Até mesmo quando a organização estrutural da sociedade é mencionada, esta tende a ser pensada fora de sua especificidade. Assim, o que é específico do modo de produção capitalista tende a ser configurado como algo da 'Modernidade', da 'sociedade disciplinar', da 'sociedade normalizadora' ou simplesmente como algo da 'sociedade'. Em qualquer uma dessas denominações, o específico, isto é, o modo de produção capitalista, não é evidenciado. Para Marques (2001, p.51), o processo de segregação e discriminação dos indivíduos com deficiência

não pode ser desvinculado da concepção funcionalista de sociedade, modelo que representa bem a estrutura social vigente na Modernidade. Ao colocar as pessoas deficientes numa condição de inferioridade corpórea e de incapacidade produtiva, a sociedade gera uma extratificação com limites muito claros quanto às possibilidades de realização pessoal, profissional e afetiva de seus membros. Ao ser concebida como um corpo estruturado com órgãos e onde cada órgão tem uma função social muito precisa, a sociedade estabelece as funções de cada indivíduo e determina quem pode e quem não pode desempenhar os diversos papéis sociais. Por analogia com o corpo humano, os órgãos devem se relacionar entre si, trazendo uma harmonia fisiológica para esse corpo, não devendo existir órgãos estragados ou em mau funcionamento.

O autor reforça ainda que, na concepção funcionalista de sociedade, um corpo com órgãos 'deficientes' não é um 'corpo social' bem estruturado e em ordem, sendo, portanto, considerado fora do normal. Dois sentidos acompanham esse entendimento: o de que um órgão fora do normal causa prejuízo funcional e o de que um 'órgão estragado' pode contaminar os demais, devendo, por isso, ser afastado do conjunto de órgãos sadios.

O que Marques (2001) chama de 'concepção funcionalista de sociedade', denominação originalmente formulada por Emile Durkhein, não passa de uma 
issn: $1808-799 X$

ano 8 - número 10 - 2010

expressão específica do modo de produção capitalista da vida humana, que é a própria estrutura social vigente na modernidade. Se, por um lado, Marques (2001) demonstra que a 'concepção funcionalista de sociedade' contribuiu para efetivar a segregação das pessoas com deficiência, por outro lado, o autor não relaciona a referida concepção com o modo de controle sociometabólico do capital, do qual resultam as determinações impostas pela sociedade capitalista.

De acordo com Mészáros (2002), o sistema do capital constituiu-se, no curso da história, como uma poderosa estrutura totalizadora de controle à qual tudo deve se ajustar, inclusive os seres humanos. O autor explica que, para funcionar como modo totalizador de controle sociometabólico, o sistema do capital forma uma estrutura de comando adequada para exercer suas funções. Consequentemente, para atingir os objetivos metabólicos adotados, tudo deve se sujeitar às exigências do modo de controle do capital, cabendo, inclusive, a cada ser humano, provar sua 'viabilidade produtiva' (Mészáros, 2002).

Em relação à criação da figura do anormal, pode-se dizer que, ao não provarem sua 'viabilidade produtiva' ao capital, as pessoas com deficiência foram obrigadas a se inserir em situações determinadas pela posição política e econômica ocupada nas relações de poder. Dentre as determinações da sociabilidade capitalista daquele contexto, encontrava-se o entendimento da deficiência como anormalidade, além da segregação de seus portadores, visto que os indivíduos pertencentes a esse grupo historicamente discriminado foram tidos como economicamente improdutivos.

Essas reflexões nos permitem afirmar que, sob o ponto de vista da classe dirigente do processo histórico, a preocupação com a capacidade produtiva das pessoas, e da sociedade em geral, é elemento de fundamental importância para a construção da figura do anormal. Embora Marques (2001) reconheça essa importância, não a relaciona com a hegemonia das classes dominantes na sociedade capitalista. Talvez por tomar a modernidade sem os devidos vínculos com a história produzida por homens e mulheres reais, o autor perceba a sociedade capitalista como 'sociedade disciplinar ou normalizadora' ou como um modo de 
issn: 1808-799X

ano 8 - número 10 - 2010

produção da vida humana que não mais precisasse ser definido, bastando denominá-lo de 'sociedade'. Em suas palavras:

É com a força de trabalho que a sociedade, em última instância, se preocupa. Nesse sentido, a deficiência assume a marca da incapacidade produtiva e da dependência econômica, fazendo de seus portadores seres inadaptados aos padrões de aceitabilidade com que ela, sociedade, classifica seus membros. Um corpo improdutivo é necessariamente um corpo deficiente. E é sobre esse corpo deficiente que as relações de poder têm alcance imediato (Marques, 2001, p.58).

No entendimento de Marques (2001, p.37), "a Modernidade foi marcada pelo desejo do normal" e mais: "a anormalidade constituía uma necessidade do pensamento Moderno". Isso teria gerado a necessidade de se criar a categoria da anormalidade, para que a dicotomia normal versus anormal pudesse ser estabelecida. Com a consolidação dessa dicotomia, teria sido instaurado o paradigma da exclusão, que "entende a deficiência como anormalidade, colocando seus portadores na condição de desviantes, incapazes e doentes, ou seja, totalmente à margem do processo social" (Marques, 2001, p.49).

Para Marques (2001, p.37), o estabelecimento de padrões e 0 enquadramento das pessoas e dos comportamentos dentro ou fora dos mesmos é um exemplo do "esquema de vigilância e controle típico da Modernidade". Daí a padronização dos indivíduos em normais e anormais e a segregação dos considerados desviantes em instituições especializadas.

Sob o ponto de vista do autor, portanto, o 'paradigma da exclusão' estaria pautado genericamente no pensamento moderno, sobretudo porque apresenta como marca a identificação da diferença como desvio e a norma como instrumento disciplinar: 
issn: 1808-799X

ano 8 - número 10 - 2010

Identificada como uma marca do pensamento Moderno, a caracterização da deficiência como anormalidade constitui uma primeira formação discursiva, a qual traz implícito o referencial de normalidade como parâmetro para tal caracterização. O que está em jogo é, na verdade, a apologia do normal. A anormalidade não passa, pois, do contraponto necessário para a construção do sentido de normalidade (Marques, 2001, p. 50).

Nesse ponto, é importante ressaltar a seguinte afirmação de Malik (1999): os pós-modernos costumam interpretar problemas do século XX como consequência da 'modernidade' e não como produto de relações sociais específicas, fazendo com que problemas específicos criados pelo capitalismo percam seu caráter histórico, ou seja, ao invés de serem investigados em sua especificidade, "são reunidos num saco de gatos como conseqüência geral da 'modernidade'" (Malik, 1999, p.142).

Considerar o mecanismo de criação da figura do anormal como uma espécie de consequência da 'modernidade' acarreta duas implicações centrais. Primeiramente, isenta-se o modo de produção capitalista de sua culpa na constituição de todo o processo de segregação dos desviantes. Outra forma de atuação importante é que, ao atribuir ao 'pensamento moderno' a culpa pelo mecanismo de criação da figura do anormal, torna-se 'incoerente' buscar a superação desse mecanismo com base no próprio 'pensamento moderno'. Consequentemente, em prol da adoção do pós-modernismo, são descartadas as teorias críticas pautadas nos preceitos da Modernidade, dentre elas, a concepção de mundo empenhada em superar todas as formas de desigualdade, exploração e dominação social, política e econômica. Assim, o enfrentamento da segregação dos considerados desviantes tende se sintonizar com os interesses e necessidades do bloco dirigente da atual etapa capitalista.

A tentativa de explicar o processo de criação e segregação do 'anormal' com base nos preceitos pós-modernos dificulta, ou até mesmo impede, a compreensão desse processo como síntese de múltiplas determinações. Para alcançar essa compreensão, seria necessário considerar que o mecanismo de criação da figura do anormal foi incorporado e aprofundado pelo modo capitalista de produção da 
existência humana e pelas relações sociais nele constituídas. No entanto, isso evidenciaria a atuação estratégica do bloco dirigente da sociedade capitalista na constituição do referido processo. Nesse ponto, torna-se possível compreender por que ao pós-modernismo não interessa considerar o processo de criação da figura do anormal como parte integrante de uma totalidade concreta. Busco a explicação disso nas palavras de Eagleton (1998, p. 20): "Não buscar a totalidade representa apenas um código para não se considerar o capitalismo", ou seja, o pós-modernismo desconsidera a categoria totalidade, tornando possível atribuir a culpa do processo de segregação dos desviantes à 'Modernidade' e não ao modo de vida gerado no capitalismo.

Em relação ao fato de adotar a concepção pós-moderna de poder, a estratégia não se diferencia muito, pois considerar que o mecanismo de criação da figura do anormal é um dos efeitos dos micropoderes capilares implica aceitar o pressuposto de que tal mecanismo não foi colocado em prática por processos de hegemonia presentes na totalidade da vida social.

É importante reconhecer a perversidade do processo de segregação identificado e analisado por Marques (2001), L. Marques (2001) e Marques e Marques (2003), mas atacar a 'Modernidade' de maneira genérica, sem considerá-la na história, não é a melhor escolha para os que interpretam os fenômenos da sociedade capitalista como parte integrante da totalidade concreta.

À primeira vista, o denominado paradigma da exclusão aparenta ser uma forma de segregação desvinculada da totalidade da vida social, decorrente de micropoderes difusos e capilares que não emanam das relações sociais de produção. Analisada na totalidade, porém, essa segregação revela algo distinto, tal como será evidenciado na seção a seguir.

Além de contribuir para que o fenômeno da segregação de grupos historicamente discriminados seja compreendido como resultado de outra lógica que não a das relações sociais entre desiguais, os estudos de Michel Foucault - e de outros autores que compartilham de suas formulações - têm contribuído para que a 
issn: $1808-799 \mathrm{X}$

ano 8 - número 10 - 2010

essência de tal fenômeno seja confundida com sua manifestação imediata. Isso permite que a segregação dos desviantes do padrão de normalidade seja considerada uma exclusão, isto é, "um sistema em que alguém fica totalmente de fora" (Santos, 2007, p.63).

Segundo Fontes (2005), o fato de grandes parcelas da população terem ficado de fora do processo de assalariamento durante longos períodos não significa que tenham permanecido fora das relações capitalistas, já que, para caracterizar algum grupo social como permanecendo 'fora do mercado', seria necessário que ele fosse capaz de garantir sua subsistência de modo independente das formas mercantis ou recorrendo a elas apenas de maneira acessória. Seguindo essa mesma lógica, pode-se compreender a segregação de grupos historicamente discriminados não mais como uma exclusão, visto que os grupos em tese 'excluídos' ainda se encontram no interior das relações sociais capitalistas.

A afirmação de que grupos sociais foram excluídos, isto é, mantidos totalmente de fora, desconsidera que, independentemente da forma pela qual as populações ou grupos sociais se conectam às relações sociais capitalistas, todos fazem parte dessas relações, sendo de alguma forma afetados por elas. Inúmeros acontecimentos, fatos, fenômenos que, à primeira vista, parecem absolutamente independentes, formam, na verdade, um sistema cuja coesão é garantida pelo princípio do capital que submete todos e cada elemento da vida social à sua lógica (Oliveira, 2004b). A partir dessa submissão à intenção e objetivação do contínuo acúmulo de capital, inúmeros grupos sociais são obrigados a se adequarem ao modo de vida exigido pelo bloco no poder. Dentre tais formas de enquadramento, encontra-se a segregação dos indivíduos considerados anormais, que se configura como uma 'exclusão interna' (Fontes, 2005) e não como uma exclusão do sistema enquanto tal.

Portanto, embora a segregação das pessoas com deficiência aparente ser um processo em que tais indivíduos ficam 'totalmente de fora', esse fenômeno não configura uma exclusão do sistema, pois a margem do convívio social ainda é parte integrante das relações sociais capitalistas. 
issn: 1808-799X

ano 8 - número 10 - 2010

\section{A essência da 'exclusão'}

Os temas referentes ao que atualmente se denomina de 'exclusão social' foram analisados, ao longo deste século, em sua maioria, a partir do entendimento de que a exclusão seria uma forma passageira de um desequilíbrio ou uma disfunção social ou, ainda, uma inadaptação individual (Fontes, 2005).

Em oposição a essas compreensões, encontram-se as análises que partem do pensamento de Marx (2008), a exemplo dos estudos de Oliveira (2004a), Oliveira (2004b) e Fontes (2005), que evidenciam a relação da 'exclusão' com a dinâmica capitalista. Para compreender a essência da 'exclusão', faz-se necessário retomar algumas reflexões de Marx, mais especificamente aquelas relacionadas ao processo de acumulação primitiva.

Marx (2008) explica que o acúmulo de capital pressupõe a produção capitalista, e esta, a existência de grandes quantidades de capital e de força de trabalho nas mãos dos produtores de mercadorias. Mas, para estabelecer esses fatores, foi necessário realizar um intenso processo de expropriação, uma espécie de acumulação primitiva, história inscrita a sangue e fogo nos anais da humanidade (Marx, 2008). Em síntese, pode-se dizer que a acumulação primitiva é o processo histórico a partir do qual foram estabelecidas as condições básicas para a acumulação capitalista:

O processo que cria o sistema capitalista consiste apenas no processo que retira ao trabalhador a propriedade de seus meios de trabalho, um processo que transforma em capital os meios de subsistência e os de produção e converte em assalariados os produtores diretos. A chamada acumulação primitiva é apenas o processo histórico que dissocia o trabalhador dos meios de produção. É considerada primitiva porque constitui a pré-história do capital e do modo de produção capitalista (Marx, 2008, p. 828).

Na história da acumulação primitiva, marcam época as transformações que serviram de alavanca à classe capitalista em formação, com destaque para os 
issn: 1808-799X

ano 8 - número 10 - 2010

deslocamentos das grandes massas humanas que foram súbita e violentamente privadas de seus meios de subsistência (Marx, 2008). Nesse processo, os camponeses foram privados de sua fonte tradicional de subsistência. Antes, eles dispunham do usufruto das terras comuns, de onde retiravam os meios necessários para sobreviver, como lenha e turfa, por exemplo. Depois, com a transformação da propriedade comunal em propriedade privada, o consumo desses meios assumiu a forma de roubo. Além disso, a expropriação dos camponeses foi marcada pela chamada 'limpeza das propriedades', que consistiu em 'varrer' destas os seres humanos, para que os trabalhadores agrícolas não encontrassem mais, na terra em que lavravam, o espaço necessário para sua própria habitação (Marx, 2008). Desse modo, a acumulação primitiva formou uma população detentora apenas de sua força de trabalho, já que muitos foram impedidos de assegurar sua própria subsistência a partir das condições anteriores de vida.

Conforme instiga Oliveira (2004a), o fenômeno da acumulação primitiva constituiu, à primeira vista, um processo de exclusão que pode ser evidenciado pelos seguintes excertos ilustrativos extraídos da obra de Marx:

“... grandes massas humanas são arrancadas súbita e violentamente de seus meios de subsistência..." (...); "A expropriação da base fundiária do produtor rural, do camponês, forma a base de todo o processo" (...); "... mediante exclusão violenta do campesinato da base fundiária...” (...); “... usurpação de sua terra comunal.” (...); “... a expropriação dos pequenos camponeses arruína o país" (...); "O processo de expropriação violenta da massa do povo recebeu novo e terrível impulso, no século XVI, pela Reforma..." (...); "... os proprietários fundiários impuseram legalmente uma usurpação, que em todo continente realizou-se sem rodeios legais." (...); “... a usurpação da terra comunal e a revolução da agricultura que a acompanhou tiveram efeitos tão agudos sobre o trabalhador agrícola.."(...); "... 15 mil habitantes, cerca de três mil famílias, foram sistematicamente expulsos e exterminados." (...); "... os 15 mil gaélicos já tinham sido substituídos por 131 mil ovelhas." (...); "Os gaélicos foram expulsos pela segunda vez" (...); "A intermitente $e$ sempre renovada expropriação e expulsão do povo do campo, como foi visto, forneceu à indústria urbana mais e mais massas de proletários, situados totalmente fora das relações corporativas...". (...); "A expropriação e a expulsão de parte do povo do campo liberam, com os trabalhadores, não apenas seus meios de 
issn: $1808-799 \mathrm{X}$

ano 8 - número 10 - 2010

subsistência e seu material de trabalho para o capital industrial, mas cria também o mercado interno." (Oliveira, 2004a, p.136, grifos do autor).

Segundo Oliveira (2004a), o processo de exclusão relatado refere-se ao ato de retirar do caminho todos os entraves ao estabelecimento das condições necessárias ao funcionamento do modo de produção capitalista. Nesse movimento, "exclui-se pela expropriação, o roubo, a expulsão, a usurpação, enfim, sempre processos de violência" (Oliveira, 2004a). Mas, como os trabalhadores que foram expulsos de suas terras não podiam ser absorvidos pela manufatura nascente com a mesma rapidez com que se tornavam disponíveis, muitos foram deslocados do centro da vida social que começava a ser delineada (Marx, 2008).

De acordo com Marx (2008, p. 848), isso ocorreu, na maioria dos casos, por força das circunstâncias, sobretudo porque os trabalhadores, ao serem "arrancados das suas condições habituais de existência, não podiam enquadrar-se, da noite para o dia, na disciplina exigida pela nova situação".

A impossibilidade de prosseguir trabalhando nas velhas condições que não mais existiam, fez, portanto, com que muitas pessoas se transformassem em 'vagabundos' e 'indigentes', transformação que Ihes era imposta. Entretanto, tal impossibilidade fez emergir também uma legislação que os tratava como pessoas que escolheram propositalmente o caminho do crime, como se dependesse da vontade deles prosseguir trabalhando nas velhas condições que não mais existiam (Marx, 2008).

Conforme explica Oliveira (2004a), a legislação a que se refere Marx não deixou de providenciar, além do enquadramento legal e da crueldade da punição, a marca infame que confere o elemento simbólico da exclusão: o estigma. A seguir, alguns exemplos da referida legislação: 
issn: $1808-799 \mathrm{X}$

ano 8 - número 10 - 2010

Henrique VIII, lei de 1530. - Mendigos velhos e incapacitados para trabalhar têm direito a uma licença para pedir esmolas. Os vagabundos sadios serão flagelados e encarcerados. Serão amarrados atrás de um carro e açoitados até que o sangue lhes escorra pelo corpo; em seguida, prestarão juramento de volta à sua terra natal ou ao lugar onde moraram nos últimos 3 anos, "para se porem a trabalhar". Que ironia cruel! Essa lei é modificada com acréscimos ainda mais inexoráveis, no ano 27 do reinado de Henrique VIII. Na primeira reincidência de vagabundagem, além da pena de flagelação, metade da orelha será cortada, na segunda, o culpado será enforcado como criminoso irrecuperável e inimigo da comunidade (Marx, 2008:848).

Eduardo VI. - Uma lei do primeiro ano de seu governo, 1547, estabeleceu que, se alguém se recusar a trabalhar, será condenado como escravo da pessoa que o tenha denunciado como vadio. $O$ dono deve alimentar seu escravo com pão e água, bebidas fracas e restos de carne, conforme achar conveniente. Tem o direito de forçálo a executar qualquer trabalho, por mais repugnante que seja, flagelando-o e pondo-o a ferros. Se o escravo desaparecer por duas semanas, será condenado à escravatura por toda a vida e será marcado a ferro, na testa e nas costas, com a letra S; se escapar pela terceira vez, será enforcado como traidor. O dono pode vendêlo, legá-lo, alugá-lo, como qualquer bem móvel ou gado. Se o escravo tentar qualquer coisa contra seu senhor, será também enforcado. (...) Se se verificar que um vagabundo está vadiando há 3 dias, será ele levado à sua terra natal, marcado com ferro em brasa no peito com a inicial $V$ e lá posto a trabalhar a ferros, na rua ou em outro serviços. Se informar falsamente o lugar de nascimento, será condenado a escravo vitalício desse lugar, dos seus habitantes ou da comunidade e marcado com S (Marx, 2008:848-849).

Elizabeth, 1572. - Mendigos sem licença e com mais de 14 anos serão flagelados severamente e terão suas orelhas marcadas a ferro, se ninguém quiser tomá-los a serviço por 2 anos; em caso de reincidência, se têm mais de 18 anos, serão enforcados, se ninguém quiser tomá-los a serviço por dois anos; na terceira vez, serão enforcados, sem mercê, como traidores (Marx, 2008:849).

Jaime I. - Quem perambule e mendigue será declarado vadio e vagabundo. Os juízes de paz, em suas sessões, estão autorizados a mandar açoitá-los e encarcerá-los por 6 meses, na primeira vez, e por 2 anos, na segunda. Na prisão, receberão tantas vezes tantas chicotadas quantas os juízes de paz acharem adequadadas. (...) Os vagabundos incorrigíveis e perigosos serão ferreteados com um $R$ sobre o ombro esquerdo e condenados a trabalhos forçados; se novamente forem surpreendidos mendigando, serão enforcados sem mercê (Marx, 2008, p.850). 
issn: $1808-799 \mathrm{X}$

ano 8 - número 10 - 2010

A partir do conteúdo dessas leis, Marx (2008, p.850-851) conclui que, por meio de um grotesco terrorismo legalizado, "a população rural expropriada e expulsa de suas terras, compelida à vagabundagem, foi enquadrada na disciplina exigida pelo sistema de trabalho assalariado".

Nesse ponto, torna-se evidente que a acumulação primitiva não consistiu apenas em um processo de exclusão das condições anteriores de existência. Concomitante à exclusão, esse processo concretiza a inclusão dos indivíduos na lógica da produção capitalista, a partir do enquadramento destes na nova disciplina exigida pelo capital (Oliveira, 2004a).

Essas reflexões fornecem valiosas pistas para o entendimento do fenômeno da segregação das pessoas com deficiência.

De acordo com Fontes (2005), a sociedade capitalista estabelece a imposição de comportamentos, normas, condutas e valores, isto é, procedimentos de inclusão forçada, que resultam em múltiplas formas de discriminação, reclusão ou segregação em seu próprio interior. Embora os procedimentos de inclusão forçada estejam sempre presentes no interior do capitalismo, estes modificam sua forma de acordo com as exigências específicas da classe dominante em cada época. Se, por um lado, no processo de acumulação primitiva, o encarceramento, a flagelação e o uso de ferro em brasa resultaram de procedimentos de inclusão forçada utilizados naquele contexto para enquadrar os 'desviantes' na lógica exigida pelo modo de produção capitalista, por outro lado, como resultado de modificações decorrentes dos processos históricos, outras formas de inclusão forçada foram configuradas, a exemplo da segregação dos indivíduos com deficiência nas instituições especializadas.

$\mathrm{Na}$ seção anterior, foi possível compreender que a segregação de grupos historicamente discriminados decorreu de um processo que criou a figura do anormal. Esse processo, embora aparente ser uma 'exclusão', decorre da própria necessidade que tem o capital de incluir os indivíduos em sua lógica. 
issn: $1808-799 X$

ano 8 - número 10 - 2010

De acordo com Platt (2004), a anormalização dos seres humanos é um processo desencadeado a partir do momento em que, para o corpo social, o indivíduo apresenta suas particularidades e estas vão se traduzindo como dados justificados ou não para sua não-pertença ao grupo social. Segundo a autora, o entendimento dessa não-pertença significa precisar quais laços coadunam para o agregamento das pessoas. Esses laços são definidos, em última instância, pelo modo de produção da existência humana, uma vez que adequação social ou normalidade e anormalidade

são conceitos construídos não a partir de uma sugerida "consciência espontânea" sobre os indivíduos que nos permite delimitar o que seria adequado (normal/anormal) ao convívio social ou não ("por designo de Deus", "má sorte", etc), mas atrelados ao processo de produção e às relações sociais desencadeadas por este, e que, por desenhar-se desta maneira, vai formatando-se historicamente (Platt, 2004, p.5).

Portanto, enquanto impera a relação social que sustenta o modo de produção capitalista, o que vem a ser considerado normal em uma dada época pode não ser considerado em outra, unicamente pela intenção e objetivação do contínuo acúmulo de capital (Platt, 2004). Como o binômio normalidade/anormalidade resulta de um consenso social concebido diante de um padrão intencionalmente formatado pelo processo das relações sociais capitalistas (Platt, 2004), a caracterização da deficiência como anormalidade pode ser entendida como manifestação de um procedimento que visou enquadrar esse grupo social na disciplina exigida pelo capital.

A partir do momento em que a deficiência passou a significar, sob o ponto de vista do bloco dominante, um risco à objetivação e ao contínuo de acúmulo de capital, foram sendo construídas estratégias para gerir esse risco, sendo a própria formulação do que é o anormal uma delas. Ao compreender que as pessoas com deficiência significavam um risco ao acúmulo de capital, o bloco no poder buscou 
issn: 1808-799X

mantê-las à margem do convívio social. Entretanto, não bastava apenas segregálas, era preciso convencer toda a sociedade quanto à legitimidade desse seu interesse específico. No intuito de convencer as pessoas de que a segregação era benéfica aos indivíduos com deficiência, intelectuais orgânicos da classe dominante, os especialistas, formularam e difundiram a ideia de que essas pessoas eram anormais e, por isso, precisavam ser internadas em instituições especializadas. Difundidas por todo o tecido social, essas ideias formuladas pelo bloco no poder foram se reproduzindo na sociedade.

Ainda que a segregação desse grupo historicamente discriminado apareça como uma questão social resultante do chamado paradigma da exclusão, é importante salientar que essa segregação não se reveste de um caráter de originalidade, pelo contrário, consiste na fase mais recente de um longo processo. A segregação das pessoas com deficiência nas instituições especializadas corresponde a uma 'exclusão' do convívio com as pessoas consideradas normais; mas, ao mesmo tempo, essa segregação corresponde à inclusão desses indivíduos na lógica exigida pelo capitalismo. Portanto, em essência, esse processo corresponde a um procedimento mais recente de inclusão forçada, que enquadrou os 'desviantes' na disciplina exigida pelo capital.

\section{Nota conclusiva}

Ao evidenciar o vínculo da 'exclusão' com os processos históricos, o presente texto comprova que o modo como o pós-modernismo capta a segregação das pessoas com deficiência acaba por se alinhar aos interesses do bloco no poder, sobretudo porque mantém lacunas entre o fenômeno social em questão e as determinações impostas pelas relações sociais de produção.

Ao contrário do que defende a abordagem pós-moderna, acreditamos que o fenômeno frequentemente denominado de exclusão é resultado de processos de hegemonia estabelecidos no capitalismo. Assim, entendemos que as condições de inferioridade social que atingem as pessoas com deficiência só podem ser resolvidas 
issn: $1808-799 \mathrm{X}$

ano 8 - número 10 - 2010

com a superação do capitalismo, visto que, em essência, tais condições resultam de procedimentos de inclusão forçada estabelecidos para garantir o acúmulo de capital.

\section{Referências}

CHAUÍ, Marilena. Escritos sobre a universidade. São Paulo: Editora UNESP, 2001. EAGLETON, Terry. As ilusões do pós-modernismo. Rio de Janeiro: Jorge Zahar, 1998.

EAGLETON, Terry. Depois da teoria: um olhar sobre os estudos culturais e o pósmodernismo. Rio de Janeiro: Civilização Brasileira, 2005.

FONTES, Virgínia. História e Verdade. In: FRIGOTTO, Gaudêncio; CIAVATTA, Maria (orgs.). Teoria e educação no labirinto do capital. 2. ed. Petrópolis: Vozes, 2001.

FONTES, Virgínia. Reflexões im-pertinentes: história e capitalismo contemporâneo. Rio de Janeiro: Bom Texto, 2005.

FOUCAULT, Michel. Microfísica do poder. 14. ed. Rio de Janeiro: Graal, 1999.

GLAT, Rosana; FERNANDES, Edicléa Mascarenhas. Da segregação à educação inclusiva: uma breve reflexão sobre os paradigmas educacionais no contexto da Educação Especial brasileira. Inclusão (Brasília), Brasília/DF, v. 1, n. 1, p. 35-39, 2005.

GRAMSCI, Antonio. Cadernos do cárcere. Vol. 3. Maquiavel. Notas sobre o Estado e a política. Rio de Janeiro: Civilização Brasileira, 2000.

HARVEY, David. Condição pós-moderna. Uma pesquisa sobre as origens da mudança cultural. 16. ed. São Paulo: Loyola, 2007.

KOHAN, Néstor. Gramsci e Marx: hegemonia e poder na teoria marxista. Tempos Históricos (EDUNIOESTE), v.10, p.15-70, 2007.

KOSIK, Karel. Dialética do concreto. 3. ed. Rio de Janeiro: Paz e Terra, 1985.

MALIK, Kenan. O espelho da raça: o pós-modernismo e a louvação da diferença. In: WOOD, Ellen Meiksins; FOSTER, John Bellamy (orgs.). Em defesa da história: Marxismo e pós-modernismo. Rio de Janeiro: Jorge Zahar, 1999.

MARQUES, Carlos Alberto. A imagem da alteridade na mídia. Rio de Janeiro, CFCH/ECO, Tese de Doutorado, 2001.

MARQUES, Carlos Alberto; MARQUES, Luciana Pacheco. Do universal ao múltiplo: os caminhos da inclusão. In: LISITA, Verbana Moreira S. S.; SOUSA, Luciana Freire E. C. P. (orgs.) Políticas educacionais, práticas escolares e alternativas de inclusão escolar. Rio de janeiro: DP\&A, 2003.

MARQUES, Luciana Pacheco. O professor de alunos com deficiência mental: concepções e práticas pedagógicas. Juiz de Fora: Editora UFJF, 2001.

MARX, Karl. O capital. Crítica da economia política. Livro 1. Volume 2. 22. ed. Rio de Janeiro: Civilização brasileira, 2008.

MÉSZÁROS, István. Para além do capital. São Paulo/Campinas: Boitempo/Editora da UNICAMP, 2002.

OLIVEIRA, Avelino da Rosa. Marx e a exclusão. Pelotas: Seiva, 2004a.

OLIVEIRA, Avelino da Rosa. Sobre o alcance teórico do conceito de exclusão. Civitas, Porto Alegre, v.4, n.1, jan-jun. 2004b. 
issn: $1808-799 \mathrm{X}$

ano 8 - número 10 - 2010

PLATT, Adreana Dulcina. O paradigma inclusivo das políticas educacionais e o paradigma excludente ds políticas econômicas nos anos 90: o constructo sócioconceitual da normalidade/anormalidade (ou adequação social). Campinas, Faculdade de Educação/ Universidade Estadual de Campinas, Tese de Doutorado, 2004.

SADER, Emir. O poder, cadê o poder? Ensaios para uma nova esquerda. São Paulo: Boitempo, 2003.

SANTOS, Boaventura de Sousa. Renovar a teoria crítica e reinventar a emancipação social. São Paulo: Boitempo, 2007.

VEIGA-NETO, Alfredo. Foucault \& a educação. 2. Ed. Belo Horizonte: Autêntica, 2005.

1 Este texto apresenta reflexões contidas na dissertação As ilusões do paradigma da inclusão na produção teórica da educação física. Financiada pela CAPES, essa dissertação foi elaborada por Leonardo Docena Pina, sob orientação do prof. Dr. André Silva Martins, no curso de Mestrado do Programa de Pós-graduação em Educação da Universidade Federal de Juiz de Fora.

2 De acordo com Gramsci (2000), hegemonia é uma relação de poder presente no capitalismo que expressa a dominação de uma ou mais frações de classe sobre o conjunto de sua própria classe e das classes antagônicas, em que o econômico e o político expressam a 'direção moral e intelectual' a ser seguida pelo conjunto da sociedade.

3 Entende-se o pós-modernismo como um subproduto do modo de vida do novo regime de acumulação do capital. Conforme Eagleton (2005), "pós-moderno" refere-se ao movimento do pensamento contemporâneo que rejeita totalidades, valores universais, grandes narrativas históricas, sólidos fundamentos para a existência humana e a possibilidade do conhecimento objetivo. Esse autor explica que a palavra pós-modernismo refere-se, em geral, a uma forma de cultura contemporânea, enquanto o termo pós-modernidade alude a um período histórico específico (Eagleton, 1998). Segundo ele, "Pós-modernidade é uma linha de pensamento que questiona as noções clássicas de verdade, razão, identidade e objetividade, a idéia de progresso ou emancipação universal, os sistemas únicos, as grandes narrativas ou os fundamentos definitivos de explicação. Contrariando essas normas do iluminismo, vê o mundo como contingente, gratuito, diverso, instável, imprevisível, um conjunto de culturas ou interpretações desunificadas, gerando, um certo grau de ceticismo em relação à objetividade da verdade, da história e das normas, em relação às idiossincrasias e a coerência de identidades" (Eagleton, 1998, p. 7).

4 Recorreu-se às formulações desses autores porque ambos são referência no campo educacional. Além disso, chama a atenção o fato de que suas formulações identificam e descrevem a 'exclusão' das pessoas com deficiência, mas, ao mesmo tempo, como é típico do pensamento pós-moderno, prezam a superfície do aparecer social e não captam a essência do fenômeno em questão.

5 O autor não utiliza o termo 'pós-modernidade'. Diz ele: "Por opção, o pensamento denominado de Pós-Modernidade por alguns autores será denominado, aqui, por 'Atualidade'” (Marques, 2001, p.29).

6 Modernidade é definida por Marques (2001, p. 32) como sociedade disciplinar ou normalizadora, que "pode ser caracterizada como um ambiente repleto de confinamentos, cada qual com suas leis e sanções disciplinares próprias". No entendimento do autor, a vigilância e o controle constituem a 'sociedade disciplinar', reafirmando o que Foucault (1999) denominou de microfísica do poder. 
issn: 1808-799X

ano 8 - número 10 - 2010

Leonardo Docena Pina é Mestre em Educação pela Universidade Federal de Juiz de Fora (UFJF) e Licenciado em Educação Física por essa mesma instituição. Atualmente, é professor da rede pública municipal de ensino de Angra dos Reis e integrante do Núcleo de Estudos sobre Trabalho e Educação da UFJF.

André Silva Martins é Doutor em Educação pela Universidade Federal Fluminense (UFF), é professor da Faculdade de Educação da Universidade Federal de Juiz de Fora (UFJF) onde integra o Programa de Pós-Graduação em Educação e coordena o Núcleo de Estudos sobre Trabalho e Educação. 